\title{
Lugares, ações e intenções como possibilidades de análise: discursos sobre a escola primária rural e a formação de seus professores (Santa Catarina 1942-1955)
}

\author{
Elaine Aparecida Teixeira Pereira* \\ Maria das Dores Daros ${ }^{* * *}$
}

\section{Resumo}

O artigo tem como foco a análise de discursos produzidos sobre a escola primária rural catarinense e a formação de seus professores, os quais ora exaltavam a excelência de tal escola e formação, ora qualificavam-nas como precárias e deficientes. A partir de fontes de pesquisa, como livros, publicações oficiais, relatórios de órgãos ligados à educação, mensagens de governadores, a análise apoia-se em autores como Quentin Skinner e Pierre Bourdieu, além de Carlos Eduardo Vieira, que sugerem uma atenção especial ao lugar de onde falam os agentes sociais, a suas intenções ao escrever, bem como aos embates relacionados aos discursos produzidos. Produto das formulações de agentes ligados ao campo educacional em situações de interlocução e na atuação pública, os discursos intelectuais estão relacionados ao arcabouço teórico, ideológico e linguístico disponível em seu contexto de produção, são transversalizados por questões, debates, embates aí postos, e estão ligados a projetos e a programas de ação. Os discursos aqui analisados propõem ações e intervenções no campo educacional e apresentam contradições nas avaliações acerca da qualidade da educação catarinense, as quais dependem das variáveis utilizadas para medir tal "qualidade" e estão relacionadas às intenções e aos lugares de onde falam os autores dos discursos.

Palavras-chave: Escola Primária. Formação de Professores. Educação Rural.

\footnotetext{
* Mestre em Educação pela Universidade Federal de Santa Catarina (UFSC). Professora no Curso de Pedagogia do Centro Universitário Municipal de São José (USJ).

** Doutora em Educação pela Universidade de São Paulo (USP). Professora titular aposentada/voluntária no Programa de Pós-Graduação em Educação da Universidade Federal de Santa Catarina (UFSC).
} 


\section{Introdução}

Este artigo $^{1}$ tem como foco a análise de discursos produzidos sobre a escola primária rural catarinense e a formação de seus professores, os quais ora exaltavam a excelência de tal escola e formação, ora qualificavam-nas como precárias e deficientes. Essa foi uma constatação a que se chegou a partir do acesso a algumas fontes de pesquisa, como livros, publicações oficiais, relatórios de órgãos ligados à educação, mensagens de governadores, produzidas entre os anos 1942 e 1955 por intelectuais ou outros agentes ligados ao campo educacional, que usavam de dados "objetivos" para sustentar avaliações acerca da educação levada a efeito em Santa Catarina.

Em algumas situações, os discursos, em princípio contraditórios, foram formulados por intelectuais pertencentes a um mesmo grupo, como é o caso de Manoel Bergström Lourenço Filho e João Roberto Moreira, ambos ligados ao Instituto Nacional de Estudos Pedagógicos (Inep), que afirmam, com base em seus estudos e pesquisas, que a escola primária presente em Santa Catarina e a formação de professores para este nível de ensino eram referência nacional dada a sua qualidade - no caso do primeiro -, ou deixavam muito a desejar e haviam inclusive regredido nos aspectos positivos que em momento pretérito chegaram a possuir - no caso do segundo.

Os discursos aqui analisados tem relação com os debates que circulavam no Brasil de meados do século XX acerca da educação, de uma maneira mais ampla, e sobre a educação dos meios rurais, de forma mais específica. Uma das críticas em curso era a de que, enquanto nas cidades já se havia alcançado avanços em matéria educacional, no campo, por sua vez, estava quase tudo por ser feito. Expandir a escola primária às mais longínquas regiões do Brasil e dotá-la de professores formados em parâmetros científicos (em cursos criados para tal fim e atendendo ao objetivo de refutar o que de espontâneo ainda estivesse presente nessa formação) eram questões que apareciam nos discursos como fins a serem perseguidos.

Tendo isso posto, algumas indagações se colocam: o que dizem os discursos acerca da escola primária presente em Santa Catarina em meados do século XX, especialmente aquela localizada nos meios rurais, e em relação à formação dos professores a atuarem/atuantes nessas instituições educacionais? O que embasa as opiniões veiculadas nos discursos acessados?

Possíveis explicações para tais tomadas de posição puderam ser formuladas com o apoio de Quentin Skinner (1996, 2005). Como um dos fundadores do "contextualismo linguístico"2, o historiador britânico adverte que a leitura de textos precisa ser realizada de modo a integrá-los nos 
contextos culturais em que foram produzidos, não sendo possível estudar o que um escritor disse sem estabelecer variadas relações que contribuam para situar o que foi dito. Ao invés de pensar os significados de forma isolada e pré-determinada, Skinner (2005) assinala que deve haver uma preocupação com os usos a que estão sujeitos os discursos, o que depende do contexto e da forma como são movimentados. As funções que as palavras podem desempenhar, assim como as múltiplas manipulações das quais são passíveis as linguagens, são princípios acompanhados da afirmação de que, para compreender um texto, é preciso saber o que os autores estavam fazendo quando de sua formulação, conhecendo, tanto quanto possível, as ações e intenções subjacentes ao que foi dito.

Outro autor importante à análise foi o sociólogo Pierre Bourdieu (1983, 1990, 1992, 2004), especialmente no que se refere ao seu conceito de "campo", que forneceu a lente por meio da qual foi vista a sociedade e situada a educação. Como microcosmo social dotado de certa autonomia, com leis e regras próprias, ao mesmo tempo em que influenciado e relacionado a um espaço social mais amplo, o campo é lugar de embates, tensões, relações de poder entre os agentes que o integram e que buscam manter ou alcançar posições. Assim é pensado, no presente artigo, o campo educacional e são situadas as ações, relações, posições e os discursos intelectuais.

Quanto ao conceito de intelectual, que vem sendo matizado com a leitura de autores como Pécaut (1990), Miceli (1979) e Mannheim (1962), vale ressaltar que, neste trabalho, tomou-se a definição explicitada por Carlos Eduardo Vieira (2007, 2008, 2011) em alguns de seus escritos, em que situa os intelectuais como agentes que compartilhavam o sentimento de identidade e pertencimento a um grupo específico, que se viam e eram vistos como portadores da importante missão de condução da sociedade. A legitimidade para o exercício de tal missão lhes era conferida pela capacidade técnica, formação escolar e familiaridade com a "cultura", por falarem de um lugar que tornava possível a síntese dos interesses sociais, e, consequentemente, a possibilidade de elaboração de projetos de intervenção para esta realidade. A defesa da centralidade da educação na reforma social, por meio da ação do Estado, também está relacionada à versão moderna do conceito.

A partir do anteriormente explicitado, os discursos são aqui compreendidos como sociais e políticos, como produção dos intelectuais ou de agentes ligados ao campo educacional em situações de interlocução. Relacionados ao contexto em que são gestados, bem como aos debates, questões, embates, aceitações e recusas por parte daqueles que os formulam e/ou contribuem para sua circulação, estão imbricados ao arcabouço teórico, ideológico e linguístico presente em tal contexto. Dessa forma, os aspectos culturais e sociais imprimem sua ação nos discursos formulados, que têm tanto a função de 
comunicar quanto a de apreciar, ou ainda a de ditar normas e construir verdades. Pressupondo ações e intenções, os discursos são também determinados por aquilo que seus autores estavam fazendo quando os formularam.

Nessa direção, a fim de atender ao objetivo de analisar discursos produzidos sobre a escola primária rural catarinense e a formação de seus professores, o presente escrito foi dividido em outras três seções: as duas primeiras focam a escola primária e a formação dos docentes a atuarem/atuantes nessa instituição; a terceira, à guisa de conclusão, traz algumas interpretações acerca dos discursos apresentados, relacionadas aos seus lugares de produção e às prováveis intenções dos que os formularam.

\section{A escola primária catarinense: referência nacional?}

Em discurso introdutório ao boletim Organização do Ensino Primário e Normal: Estado de Santa Catarina, lançado pelo Inep, Lourenço Filho (1942) tece uma avaliação bastante otimista em relação à situação educacional de Santa Catarina. Anunciando os avanços do ensino primário, afirma o diretor do Instituto:

O Estado de Santa Catarina vem, desde algum tempo, mantendo o primeiro lugar, entre tôdas as demais unidades federadas, quanto aos índices gerais de disseminação do ensino primário. É de notar-se que as taxas, pelas quais se pode julgar o rendimento do trabalho escolar, tem-se aí apresentado também, a partir de 1939, como das mais expressivas. (LOURENÇO FILHO, 1942, p. 7) ${ }^{3}$.

Ainda de acordo com Lourenço Filho (1942), apesar de gastar em educação um valor considerável, proporcionalmente a sua receita, Santa Catarina não era um dos estados que mais destinava verbas para este setor na relação "por habitante" ou "por aluno-ano". Devido a este motivo, concluía que, além dos recursos financeiros, não importavam menos as "normas e métodos de administração", que influíam "para os excelentes resultados que apresenta [Santa Catarina], como se poderá presumir também pelo intenso reajustamento de sua legislação escolar, realizado nos últimos tempos" (LOURENÇO FILHO, 1942, p. 7).

Diretor do Inep desde 1938, Lourenço Filho havia atuado como professor e diretor de escola normal e como reformador do ensino, tendo implementado, em 1922, uma reforma da Instrução Pública no Ceará. Figurou como representante do movimento pela Escola Nova no Brasil, publicando Introdução ao estudo da Escola Nova e Testes ABC. Organizou, na década de 1920, a coleção 
"Bibliotheca de Educação", considerada a primeira série de textos de divulgação pedagógica no Brasil e, entre as décadas de 1950 e 1970, publicou a Série de Leitura Graduada Pedrinho. No Inep participou de uma série de projetos, como a Revista Brasileira de Estudos Pedagógicos (Rbep) ${ }^{4}$, do qual foi fundador e trabalhou até 1964, e o plano de reforma educacional elaborado, nos anos 1950, para o Estado de Santa Catarina.

Segundo Gil (2008), dentre as atividades realizadas pelo Inep está a divulgação de informações via materiais impressos. É o caso da série de Boletins, editados entre os anos de 1939 e 1952 com o fim de "divulgar dados sobre o ensino primário nos Estados, informando sobre sua legislação, sobre a estrutura de sua administração e sobre seu desempenho quantitativo" (GIL, 2008, p. 45). Para a autora, os índices educacionais publicados pelo Inep tinham a função de hierarquizar os estados, por meio de discursos que ditavam modelos e exemplos a serem seguidos. Nesses documentos, o aspecto fragmentário da educação no país e a ausência de dados numéricos são apontados como lacunas a serem solucionadas.

A verificação e a avaliação dos aspectos ligados à educação dariam instrumentos para uma reordenação deste setor, via "racionalização da administração educacional" (GIL, 2008, p. 47). Para tanto, chegar às unidades da federação, mesmo às mais distantes, levando conhecimentos técnicos, era imperativo. Ao mesmo tempo, identificar as "situações modelares a serem seguidas" não parecia menos importante, uma vez que este objetivo constituía-se em elemento central dos discursos produzidos que, propondo-se "descritivos", acabavam por agir como "performáticos"5 (GIL, 2008, p. 48-49).

Na leitura de Lourenço Filho (1942, p. 7), uma das causas do destaque que merecia Santa Catarina estava relacionada à reforma na legislação educacional "procedida especialmente a partir de 1938", na qual houve a adoção de "normas de mais eficiente planejamento e controle dos serviços, bem como de reajustamento do trabalho do ensino às novas necessidades sociais do Estado". Dentre outros feitos, tal reformulação ${ }^{6}$ teria expedido medidas de obrigatoriedade da matrícula e frequência das crianças à escola, com destaque para o certificado de “quitação do dever escolar".

Plano ainda não experimentado no país (LOURENÇO FILHO, 1942), a quitação consistia num atestado fornecido pelo diretor ou pelo professor do estabelecimento de ensino primário, contendo nome, nacionalidade, estado civil, profissão e residência do interessado, bem com o nome e a idade $\mathrm{da}(\mathrm{s})$ criança(s) sob sua responsabilidade, e que declarava a matrícula e frequência desta(s) na unidade escolar. Sem o atestado de quitação nenhum cidadão poderia ser admitido em serviço do Estado ou Município, receber dinheiro e efetuar transações com estas instâncias, ser promovido em cargo público, 
obter certidões negativas e atestados, dentre outros (SANTA CATARINA, 1939; D'AQUINO, 1942). Quanto à quitação escolar, Lourenço Filho (1942) assinala, antes de tudo, seu "alcance educativo":

Passa a haver, junto ao público, a compreensão de deveres reais em relação à escola. Cresce o prestígio do professor e das autoridades escolares. É exercida, de forma relativamente simples, a fiscalização geral do movimento da própria rêde de ensino existente. Estabelece-se, enfim, um serviço de censo escolar permanente, pelos resultados do qual pode o Estado rever, a cada momento, a localização das escolas e planejar a criação de novas classes. Com isso atende também à necessidade de regularização das idades de matrícula [...], em cada localidade, ou em cada distrito escolar. (LOURENÇO FILHO, 1942, p. 9).

O excerto é seguido da afirmação de que os efeitos da quitação escolar estavam sendo “animadores”, com resultados positivos nos índices de matrícula e frequência na escola primária, uma vez que no triênio anterior ao da aplicação da lei, de cada 100 alunos matriculados, apenas 70 frequentavam regularmente a escola, índice que ascendera para 74 já em 1939, até chegar a 78 no ano de 1941. Os números referentes à aprovação dos alunos para a série seguinte, por sua vez, haviam subido de $50 \%$ para $63 \%$ no mesmo intervalo de tempo. Com base nas estatísticas, Lourenço Filho (1942, p. 11) proclama: "não parece haver dúvida, pois, quanto à excelência do plano pôsto em prática" ${ }^{\prime 7}$.

No segundo volume dedicado pelo Inep ao ensino primário e normal catarinense, datado de 1950, é a vez de Murilo Braga de Carvalho assinar a introdução, pois era sua, desde 1946, a direção do Instituto. Além de estar à frente do Inep, segundo a homenagem que recebeu no ano de 1952, por ocasião da sua morte causada por acidente aéreo, o "malogrado técnico" Murilo Braga de Carvalho havia realizado "obra séria, com devotamento e competência fora do comum” (RBEP, 1952, p. 5). Como colaborador da Divisão de Seleção do Departamento Administrativo do Serviço Público (Dasp), "contribuiu para a adoção e prática do sistema do mérito" no setor; já na direção do Inep, "ampliou o programa do trabalho desse Instituto, com o desenvolvimento de um plano destinado a expandir a rede escolar primária e normal, além de cursos de aperfeiçoamento para professores do magistério primário" (RBEP, 1952, p. 5). Estava ainda, no período próximo ao falecimento, "elaborando um volume completo de indicações gerais sobre as atividades educacionais no país” (RBEP, 1952, p. 5).

Murilo Braga de Carvalho (1950, p. 7) assim se refere ao ensino primário e normal de Santa Catarina:

Uma análise acurada dos dados referentes ao ensino primário brasileiro revelará que o Estado de Santa Catarina ocupa, sem favor, posição singular no quadro geral brasileiro. E do ponto de vista de capacidade da rêde de escolas não há discussão possível: tôda 
ou quase tôda população infantil poderá ser absorvida pelas milhares de classes primárias mantidas pelos poderes públicos ou instituições privadas. E se alguma criança não vai à escola é porque os pais não foram suficientemente diligentes ou residem em algum lugar êrmo e distante dos grupos humanos que justificam a criação de uma classe.

Na sequência do texto o diretor elogia a adaptação da legislação educacional catarinense às leis orgânicas federais ${ }^{8}$. Estabelecimentos, currículos, estrutura do ensino primário encontravam-se adequados ao preconizado nacionalmente, o que sustenta a seguinte afirmação: "pode-se dizer sem receios que a melhor rêde escolar brasileira se encontra em Santa Catarina" (CARVALHO, 1950, p. $10)$.

Não obstante o "progresso quantitativo" demonstrado por Santa Catarina no tocante à educação, Carvalho (1950) cita “deficiências" nas instalações pedagógicas, que necessitavam de maiores cuidados. Por esse motivo, e no intuito de auxiliar o Estado no desenvolvimento de seu sistema educacional, o governo federal vinha buscando prestar auxílio por meio da concessão de verbas para a construção e o aparelhamento de escolas:

O Govêrno Federal, com o seu plano de ampliação da rêde do ensino primário, vem procurando auxiliar o Estado na solução de um dos seus múltiplos e agudos problemas. Assim é que, em 1946, distribuiu recursos para a construção de 28 prédios para escolas rurais, em 1947, concedeu recursos para a construção de 96 novos prédios; em 1948, mais 60 prédios, em 1949, 70 novos prédios e, finalmente, em 1950, 30, o que totaliza 284 novos prédios para as zonas rurais, onde geralmente não havia escolas adequadas. Êsses prédios, à medida que vão sendo concluídos, recebem imobiliário tanto para a sala de aula como para a residência do professor. (CARVALHO, 1950, p. 11).

Denunciando que o contingente de crianças "que não encontram oportunidade para aprender" (RBEP, 1951, p. 3) não vinha decrescendo conforme o desejado, o Ministério da Educação e Saúde, por meio do Inep, desde 1946, estava "executando um plano para o desenvolvimento da rede do ensino primário, em que são utilizados os recursos do Fundo Nacional de Ensino Primário, criado em 1942" (RBEP, 1951, p. 4). Afirmando que o objetivo era combater este déficit escolar "até sua completa erradicação", o editorial da Rbep demonstra os números de escolas criadas e as metas de continuidade do projeto, numa "nova" política de administração da educação estabelecida com o citado Fundo, por meio da qual o governo federal vinha sendo "agente eficaz no desenvolvimento da base física do precário sistema educacional existente para o ensino básico da infância brasileira” (RBEP, 1951, p. 4).

Os "múltiplos e agudos" problemas educacionais que possuía Santa Catarina, anunciados no discurso de Carvalho (1950), apesar da "posição singular no quadro geral brasileiro", pareciam 
justificar a interferência da União junto ao Estado. Gil (2008, p. 52), quando aborda a relação entre os índices educacionais publicados pelo Inep e a intervenção que indiretamente sugeriam, aponta que os rendimentos insatisfatórios anunciados nos boletins abriam precedentes para a ação do poder central nas decisões políticas locais, ação esta indicada como "necessária e legítima em função das ‘dificuldades' enfrentadas pelo Estado em questão”. Assim, além de justificar tal intervenção, os índices educacionais utilizados para afirmar a primazia de Santa Catarina em relação às outras unidades da federação, suscitam questões: o que está no horizonte quando se afirma tal posição e se estabelece um ranking entre os estados? Com base em que parâmetros isso é feito?

\section{A formação docente como um dos pilares da "posição singular" anunciada}

Santa Catarina é também lembrada por seus méritos no que se refere à educação em estudo intitulado "Preparação de pessoal docente para escolas primárias rurais", de autoria de Lourenço Filho (1953). Elaborado por solicitação da Organização das Nações Unidas para a Educação, a Ciência e a Cultura (UNESCO), o estudo foi publicado na obra La Formation Professionnelle du Personnel Enseignant Primaire (1953), além da Rbep.

Quanto ao aspecto escolhido como foco do trabalho - a formação de professores - afirma: “o pequeno Estado de Santa Catarina, cuja superfície é apenas de $95 \mathrm{mil} \mathrm{km"} \mathrm{tem} \mathrm{"50} \mathrm{estabelecimentos}$ [de ensino normal], dos quais 38 são cursos regionais, bem distribuídos". E prossegue: o "Estado é também o que melhor proporção apresenta entre a matrícula das escolas primárias urbanas e a das escolas rurais, como, aliás, seria de prever" (LOURENÇO FILHO, 1953, p. 73). Citando a política federal para o desenvolvimento do ensino normal implantada a partir de 1947, explicita a previsão de auxílio financeiro para a construção de prédios escolares, bem como medidas para a formação de professores, pois, com exceção de São Paulo, Minas Gerais e Santa Catarina, a situação dos demais estados indicava a insuficiência de escolas de formação docente, conforme demonstra o Quadro 1. 
Quadro 1 - Distribuição das Escolas Normais e Cursos Normais Regionais pelos Estados, territórios e Distrito Federal no ano de 1951

\begin{tabular}{|l|c|c|c|}
\hline Locais & Cursos Regionais & Escolas Normais & Total \\
\hline Alagoas & 2 & 4 & 6 \\
\hline Amazonas & 6 & 4 & 10 \\
\hline Bahia & 2 & 12 & 24 \\
\hline Ceará & 12 & 12 & 14 \\
\hline Espírito Santo & 1 & 13 & 22 \\
\hline Goiás & 6 & 16 & 2 \\
\hline Maranhão & 1 & 1 & 3 \\
\hline Mato Grosso & - & 3 & $\mathbf{1 3 3}$ \\
\hline Minas Gerais & 9 & $\mathbf{1 2 4}$ & 6 \\
\hline Pará & 2 & 4 & 16 \\
\hline Paraíba & 8 & 8 & 24 \\
\hline Paraná & 8 & 16 & 20 \\
\hline Pernambuco & 9 & 11 & 5 \\
\hline Piaú́ & 1 & 4 & 2 \\
\hline Rio Grande do Norte & - & 2 & 29 \\
\hline Rio Grande do Sul & 2 & 27 & 20 \\
\hline Rio de Janeiro & - & 20 & $\mathbf{5 0}$ \\
\hline Santa Catarina & $\mathbf{3 8}$ & 12 & $\mathbf{1 3 5}$ \\
\hline São Paulo & - & $\mathbf{1 3 5}$ & 4 \\
\hline Sergipe & 2 & 2 & 1 \\
\hline T. do Acre & 2 & 2 & 2 \\
\hline T. do Amapá & 1 & - & 1 \\
\hline T. do Guaporé & 1 & 1 & 11 \\
\hline T. do Rio Branco & - & 11 & 546 \\
\hline Distrito Federal & - & 434 & \\
\hline Totais & 112 & & \\
\hline
\end{tabular}

Fonte: Lourenço Filho, 1953, p. 72, grifos nosso.

O Quadro 1 explicita a condição de Santa Catarina, em um primeiro momento, privilegiada, se for tomado como referência o número de cursos destinados à formação de professores. De fato, contando com 50 deles, era superado quantitativamente apenas por São Paulo e Minas Gerais, que tinham as primeiras colocações: respectivamente, 135 e 133 unidades de formação. No entanto, a partir de um olhar mais atento, é possível perceber que essa "alta colocação" de Santa Catarina devia ao elevado número de cursos normais regionais (38 no total), que era bastante superior tanto à quantidade de escolas normais (12 no total) no próprio Estado quanto à de cursos normais regionais em funcionamento em qualquer outra região brasileira. Esta "disparidade" demonstrada pelos dados estatísticos remete a alguns questionamentos: por que Santa Catarina contava com alto número de cursos normais regionais? Seria assim tão positivo o fato de possuir elevada quantidade desses cursos? Quais as diferenças entre os quesitos necessários para a abertura e manutenção de uma escola normal e 
de um curso normal regional? Que condições de formação eram oferecidas aos futuros mestres que frequentavam os cursos normais regionais? Por que em outras unidades da federação que historicamente vinham se sobressaindo devido a suas redes educacionais - como São Paulo e o próprio Distrito Federal - não eram oferecidos cursos normais regionais?

Para Nunes (2000), os cursos normais regionais remetiam às experiências adotadas em São Paulo, na década de 1920, onde houve a implementação de uma "política popular reduzida" com a oferta de educação gratuita às crianças das camadas populares atrelada à diminuição de seu tempo de permanência na escola. Essa preparação "para o trabalho", como denomina, apresentava permanências nos anos 1940 com o movimento de "diluição" e "encurtamento" da formação docente instituído pelos cursos normais regionais que, implantados pela Lei Orgânica do Ensino Normal (Decreto-lei n. 8.530, de 2 de janeiro de 1946), "abrangiam apenas o primeiro ciclo do curso secundário e formavam regentes do ensino primário" (NUNES, 2000, p. 7).

Ao analisar a realidade de Santa Catarina, Schneider (2008) também tece críticas a esse modelo, afirmando que o crescimento das matrículas no ensino normal não esteve vinculado à preparação de um maior número de professores, mas, acima de tudo, à busca de uma formação secundária por parte dos jovens do interior, que em sua maioria não tinham acesso à outra opção de curso.

Retomando os discursos acessados nas fontes, é possível constatar que Murilo Braga de Carvalho (1950) endossa a otimista avaliação de Lourenço Filho quanto aos direcionamentos das políticas de formação dos professores catarinenses levadas a efeito em meados do século XX. Do ponto de vista defendido por Carvalho (1950, p. 10), o ensino normal seria uma das bases de sustentação das qualidades da educação no Estado, principalmente devido aos seguintes aspectos: a) a formação dos docentes - "os professôres primários [de Santa Catarina] recebem conveniente preparação profissional em dois tipos de estabelecimentos: escola normal [...] e curso normal regional”; b) o número de docentes nas escolas primárias - reveladores de significativos avanços, como o acréscimo de "mais de 150\%" de docentes atuantes (em 1932, contava-se com 1800 deles, e em 1948, com 4500); c) a adequação das instituições de ensino normal às diretrizes nacionais - "as finalidades, o currículo, a organização dêste nível no Estado, estão perfeitamente ajustados às normas recomendadas pela lei”.

Por outro lado, não tão entusiasta é a avaliação de João Roberto Moreira (1954) sobre a situação do ensino em Santa Catarina. Na obra intitulada A educação em Santa Catarina: sinopse apreciativa sobre a administração, as origens e a difusão de um sistema estadual de educação, o autor afirma que 
o sistema educacional do Estado se caracterizava, na década de 1950, pelo "rígido centralismo administrativo, expandindo-se quantitativamente, mas com escasso ou nenhum progresso qualitativo" (MOREIRA, 1954, p. 86). Prosseguindo em sua crítica, diz que tal sistema se constituía numa "massa quantitativa, pobre se a escola fôr considerada de um ponto de vista intelectualista, má se tivermos em consideração às modernas exigências educacionais" (MOREIRA, 1954, p. 87).

A obra acima mencionada integrou a Campanha de Inquéritos e Levantamentos do Ensino Médio e Elementar (Cileme), implementada em março de 1953 pelo Inep e coordenada pelo próprio Moreira, então técnico do Instituto. Anteriormente ao exercício desta função, em Santa Catarina ele fora diretor de grupo escolar, professor e diretor de curso normal, além de alguém próximo à Sociologia e a Fernando de Azevedo, divulgador dessa disciplina no Brasil e responsável pela sua inclusão nos cursos de formação de professores. A filiação de Moreira com o que Daniel (2009) chama de uma psicossociologia educacional - que representaria a primeira fase do intelectual, ainda nos anos 1930 e 1940 - e, posteriormente, com uma antropossociologia - já no período em que esteve no Inep, a partir do final dos anos 1940 - pode ter sido responsável pela sua escolha como coordenador da Cileme. Moreira assumiu ainda outros cargos em instituições vinculadas ao Inep e também alcançou projeção internacional.

$\mathrm{Na}$ mesma obra, no capítulo intitulado "O problema da formação de professores”, Moreira (1954) afirma que o modelo de formação existente em Santa Catarina no início do século XX lhe parecia adequado, embora fosse insuficiente quantitativamente e deficiente em relação à organização curricular. Apesar de não formar um número suficiente de professores, a escola normal do período era adequada às necessidades, assim como a elementar, que teria exercido o papel de uma escola de primeiras letras, agindo na redução do grande número de analfabetos existentes. A posição adotada é a de situar a década de 1910 como momento de criação de um sistema de ensino em Santa Catarina, que, com as condições disponíveis, teve sua orientação "de acordo com a filosofia educacional da época, predominantemente intelectualista" (MOREIRA, 1954, p. 13).

O autor registra avanços na formação docente nos anos 1930 ao observar professores eficientes e dedicados atuando nas escolas, postura relacionada ao ensino ministrado nos cursos de formação: "os professôres que ví trabalhando em Joinvile [Santa Catarina], no grupo de que fui diretor, também tinham passado por ela [a escola normal]. E eram eficientes, faziam a escola funcionar, tinham capacidade renovadora, se interessavam vivamente pelas questões educacionais" (MOREIRA, 1954, p. 76-77). Apontando a orientação de um currículo um pouco menos intelectualista como uma das causas 
da qualidade alcançada na formação oferecida pelas escolas normais, destaca sua característica de não ter "superfluidades", mas "programas mínimos, muito esquemáticos, despidos de minúcias e requintes culturais" (MOREIRA, 1954, p. 77). A discussão sobre os problemas de um ensino intelectualista, remontando mais enfaticamente aos embates do movimento pela Escola Nova no Brasil, apresentava permanências na pauta dos anos 1950. Moreira, que tinha relações com Fernando de Azevedo e Anísio Teixeira, além de outros líderes e integrantes do movimento, era um defensor da Escola Nova e, portanto, afinado aos projetos dos "pioneiros da educação", , tanto aos difundidos nos anos 1930 quanto às "novas" bandeiras dos anos 1950 (PEREIRA; DAROS, 2013).

Novamente de acordo com Moreira (1954), não dispondo de grandes centros urbanos e sendo um Estado ruralizado, Santa Catarina viu desenvolver quantitativamente o modelo de "escola isolada" no ensino elementar. No movimento de democratização do ensino primário, o problema da falta de professores habilitados para atender as escolas isoladas havia se agravado, necessidade que teria inspirado, em parte, a reforma do ensino catarinense de $1935^{10}$, a qual transformou as escolas complementares em escolas normais primárias, obtendo aumento quantitativo dos cursos destinados à formação docente. Alguns aspectos dessa nova organização são criticados por Moreira (1954), como a sintonia de Santa Catarina com o Rio de Janeiro, o que explicava a imediata resposta catarinense, em 1946, à Lei Orgânica do Ensino Normal, por meio da rápida promulgação de uma correlata lei estadual.

A Lei Orgânica do Ensino Normal, na opinião de Moreira (1954), havia trazido inconvenientes: os cursos normais regionais não possuíam caráter regional ou mantinham um currículo diferenciado e adequado a cada região; resultavam da transformação das escolas já existentes e traziam consigo os problemas destas; não obedeciam a um critério racional de localização (alguns estavam nos centros urbanos, a despeito da função de formar professores para os meios rurais); tinham em seu currículo diversas disciplinas, para as quais não havia professores habilitados. Essa lei também havia equiparado as unidades de formação pedagógica às outras instituições de ensino secundário, mudança que, para ele, fora responsável por uma "super-matrícula" naquelas unidades, e por sua transformação em lugar de ensino "anárquico e deficiente” (MOREIRA, 1954).

Ainda de acordo com o intelectual, apesar das iniciativas com a finalidade de resolver ou amenizar o problema da falta de educadores "tecnicamente preparados", a presença de professores sem formação atuando nas escolas isoladas não era um dado novo: "Sta Catarina sempre lutou com deficiência de pessoal especialmente formado para o magistério. Em 1940, 2/3 do professorado 
primário não tinha formação pedagógica especializada para a função", o que gerava um contingente de professores provisórios recrutados por concurso ou "exame de licença” (MOREIRA, 1954, 68-69).

Tal situação apresentava permanências na década de 1950, o que "[...] se conclui da 'Mensagem à Assembléia Legislativa', enviada pelo Governador em abril de 1953, que, de 4.818 professores, 2.783, isto é, mais da metade, é constituída por extra-numerários" que não eram formados por curso normal ou curso normal regional, mas "gente com simples curso primário, na sua maior parte" (MOREIRA, 1954, p. 69). Nessa direção:

A proliferação dos cursos normais regionais conforme padrão único, cristalizou em rotina a formação do professor rural, com desrespeito à diferenciação regional e local, bem como chocou-se com a impossibilidade de se dar, a tais cursos normais, pessoal docente capaz e adequado. Até hoje continuam os professôres provisórios de escolas isoladas, sem formação pedagógica, em proporção que ultrapassa a $50 \%$ de todo o magistério primário. (MOREIRA, 1954, p. 86-87).

Novamente contradições entre os discursos podem ser verificadas, se forem comparadas as palavras de Moreira a pronunciamentos do governo de Santa Catarina. É o que se lê em mensagem endereçada à Assembleia Legislativa, em 1955, pelo então governador do Estado, Irineu Bornhausen. Em suas palavras, alcançara sucesso a política de abertura de unidades escolares estaduais, praticada por sua gestão entre os anos de 1951 e 1954. Devido ao "interêsse e os cuidados do Govêrno na ampliação da rêde escolar" podia-se, portanto, registrar um crescendo "digno de nota": "em 1951 - 28 unidades, para em 1952 ser elevado para mais 148, subindo em 1953 para 180, para atingir, em 1954, a elevação de mais 216 novas unidades de ensino". E prossegue: "o total de 572 novas unidades escolares é prova eloqüente do amparo e proteção do Govêrno às populações escolares necessitadas. Representa [...] que o Govêrno atual, sôbre o anterior, elevou de 34,9\% o número de unidades" (BORNHAUSEN, 1955, p. 31-32).

Ainda exaltando os feitos de seu governo, Bornhausen cita a expansão do ensino normal ocorrida, em especial, devido à ampliação do ciclo ginasial, representado pelos cursos normais regionais: "a divisão do ensino normal em primeiro e segundo ciclos permitiu dar solução ao problema relativo ao provimento das escolas isoladas e das classes das escolas reunidas", uma vez que quase todos os municípios haviam sido dotados "de um estabelecimento de ensino normal do primeiro ciclo (Curso Normal Regional), formando uma rêde suficiente para, em breve, atender o provimento, por concurso, das escolas isoladas e reunidas" (BORNHAUSEN, 1955, p. 33-34). 
Tendo isso posto, uma questão parece se colocar: o que sustenta os posicionamentos explicitados?

\section{À guisa de conclusão: lugares e intenções como possibilidades de análise}

As incongruências que emergem dos discursos apresentados quando colocados em relação uns com os outros trazem uma série de questões para reflexão. Uma primeira nota pertinente é a de que procurar "a verdade" quanto aos pontos argumentados, ou eleger o texto que mais parece se aproximar “do real", não são objetivos, mesmo porque "o conceito de verdade é irrelevante na tentativa de explicação das crenças" (SKINNER, 2005, p. 2). Dialogar com discursos datados de outros momentos históricos requer pensar no contexto em que foram produzidos, nas questões que apresentavam e tentavam responder, a favor ou contra "o quê" e "quem" estavam se posicionando aqueles que os produziram e/ou divulgaram, quais intenções possuíam e o que estavam fazendo ao elaborá-los e/ou colocá-los em circulação. Considerar as relações entre autor/texto/contexto, conforme ensina Skinner (2005), parece contribuir para situar melhor os discursos em relação à materialidade de sua produção.

Pensando nessa direção, é possível inferir que o discurso do governador Irineu Bornhausen tem como uma das possíveis intenções promover os feitos de sua gestão por meio do uso de dados estatísticos, objetivos, com os quais busca demonstrar os avanços do ensino primário e da formação de professores para este nível de ensino, em solo catarinense. O elevado número de cursos normais regionais no Estado e o argumento de que eles supriam a contento a necessidade das escolas isoladas e reunidas parecem ser suficientes para atestar a qualidade da educação em Santa Catarina.

João Roberto Moreira (1954), ao contrário, fala de um lugar diferente ao escrever a obra publicada pela Cileme. Como técnico do Inep e coordenador da Campanha, ao mesmo tempo em que catarinense com histórico de atuação na educação deste Estado - tanto no ensino primário quanto na formação docente -, parece querer analisar seu objeto de estudo usando de rigor e distanciamento. Tinha a incumbência de escrever a obra que inauguraria os estudos da Cileme sobre os estados brasileiros e serviria de modelo às demais monografias, mas fazia isso não somente como pesquisador do Inep, uma vez que deveria escrever sobre o Estado em que nascera, ao qual já prestara serviços e com o qual muito possivelmente mantinha relações. Por esse motivo, certo distanciamento poderia protegê-lo de uma análise passional e de acusações nesse sentido. Mas também é possível pensar a partir de outro ponto, quando se leva em conta que a educação catarinense pode ter tomado rumos com 
os quais não concordava, ou que diferiam das opções feitas nos anos 1930 e início dos 1940, quando atuava no Estado. As contribuições e os avanços registrados no período em que esteve trabalhando na educação catarinense, na sua avaliação, podem ter sido perdidos devido a direcionamentos posteriores, e este seria um bom motivo para sustentar uma análise "severa": depreciar, de alguma forma, as diretrizes do momento, exaltando os feitos pretéritos, que estavam ligados às suas contribuições.

A apreciação “do Inep” dos anos 1942 e 1950, primeiramente com os discursos de Manoel Bergström Lourenço Filho (1942, 1953) e posteriormente com os de Murilo Braga de Carvalho (1950), parece estar apoiada em uma abordagem de certa forma quantitativa. A escolha de alguns indicadores para a avaliação da educação em Santa Catarina a coloca na condição de modelo educacional do país e está diretamente relacionada aos resultados obtidos, que poderiam ser outros, caso também o fossem os aspectos mensurados.

Os estudos e as publicações do Inep durante a gestão de Lourenço Filho trazem um perfil moderno de análise e avaliação da educação nacional por meio do uso de dados racionais, produzidos com base na realidade de cada uma das unidades federadas. Esse perfil parece constituir-se num antecedente das pesquisas que viriam a ser realizadas no período em que Anísio Teixeira esteve à frente do Inep (entre 1952 e 1964), quando optou por vincular pesquisa, planejamento e aplicação de recursos na educação, por meio, dentre outras iniciativas, da realização de inquéritos e campanhas embasados nas Ciências Sociais.

Murilo Braga de Carvalho, com a incumbência de administrar os recursos do Fundo Nacional do Ensino Primário, concentrou-se no projeto de ampliação e melhoria do ensino primário e normal via construção e aparelhamento de prédios escolares, bem como pela concessão de bolsas de estudos para o aperfeiçoamento de professores primários. Esse movimento gerou um aumento da matrícula escolar, continuando presentes, entretanto, outros problemas (TIBALLI, 2008; MENDONÇA; XAVIER, 2006). Parece ser também desta ótica - a da integração nos projetos desenvolvidos por sua gestão e do avanço nos índices educacionais - que avalia a qualidade educacional alcançada por Santa Catarina.

Além de hierarquizar e prescrever, os discursos de Lourenço Filho (1942, 1953) e Carvalho (1950) assumem uma função que remete à forma como Gil (2008) caracteriza as estatísticas educacionais: a de instrumentos que servem à avaliação, ao planejamento e à aplicação de recursos na educação. Assim, mostrando a incapacidade do governo local para resolver os problemas ainda persistentes no setor educacional, a intervenção da União é justificada - e tomada apenas do ponto de vista de suas contribuições, como resposta a uma demanda. É o caso dos acordos para a viabilização de 
instalações escolares, que aparecem no texto de Carvalho (1950) justamente na forma de auxílios, com a finalidade de suprir as "deficiências" ainda verificadas na educação catarinense.

Foi possível constatar, assim, permanências nos discursos (e ações) produzidos pelo Inep nas gestões de Lourenço Filho, Murilo Braga de Carvalho e Anísio Teixeira, mas também descontinuidades. Apesar de apresentarem intersecções e consonâncias, é importante salientar que se trata de projetos educacionais, o que pode contribuir para situar os posicionamentos de seus representantes. Outras pesquisas, nesse sentido, poderiam contribuir para montar um quadro mais detalhado sobre o que cada um deles estava fazendo e sobre as intenções que moviam, ao menos em parte, seus projetos.

Os discursos que serviram como fontes ao presente artigo propõem ações e intervenções no campo educacional, construindo interpretações, prescrevendo e legitimando práticas. As análises demonstram contradições nas avaliações acerca da qualidade da educação catarinense, conclusões, em sua maioria, ancoradas nas estatísticas educacionais. O que se percebe é uma distinção nas variáveis utilizadas para medir a "qualidade" das escolas primárias e de formação de professores: embasando as avaliações mais positivas recebem destaque a quantidade de instituições de ensino, sua distribuição no Estado, a aplicação de recursos na educação, o número de alunos frequentando as escolas; já as que tecem maiores críticas à condição educacional de Santa Catarina apoiam-se na filosofia das escolas primárias e de preparação de professores, nos fins da educação, nos métodos de ensino, nos interesses do público que vinha frequentando os cursos de formação docente.

De todo modo, aqui está em pauta o uso de dados estatísticos e objetivos como integrantes de um processo de racionalização e modernização da esfera pública, falando de modo mais geral, e da modernização educacional, pensando de forma específica. A busca pela racionalização da administração, já verificada em décadas anteriores no Brasil, culmina, por exemplo, na disseminação da prática do planejamento, nos anos 1950, como via para que se alcançasse a modernização das formas de operar a administração pública, na contracorrente de práticas patrimonialistas e clientelistas de governar.

Enfim, considerar o lugar de onde falam os agentes que formulam os discursos, assim como - a partir da relação entre autor/texto/contexto - inferir sobre suas possíveis intenções, coloca-se como instigante possibilidade de análise e de reflexão acerca da temática das escolas primárias dos meios rurais e da formação de seus professores. 

seus professores (Santa Catarina 1942-1955)

\section{Notas}

${ }^{1}$ Uma versão preliminar do trabalho foi apresentada no X Congresso Luso-Brasileiro de História da Educação, realizado em agosto de 2014, na Pontifícia Universidade Católica do Paraná (PUC/PR), em Curitiba.

${ }^{2}$ Dentro do que poderia ser denominada tradição inglesa da história intelectual, alguns autores se unem em torno da abordagem que ficaria conhecida por "contextualismo linguístico" ou "Escola de Cambridge". Além de Quentin Skinner, são também representantes do contextualismo John Pocock e John Dunn, apesar de o primeiro ter sido "quem mais obstinadamente dedicou-se à dupla tarefa de invectivar contra as abordagens concorrentes e formalizar a metodologia contextualista" (SILVA, 2010, p. 300).

${ }^{3}$ Este discurso de Lourenço Filho foi também localizado no Anuário Catarinense, número 2, de 1949, onde é citado no item "O primeiro lugar no Brasil", que abre a matéria intitulada "A educação em Santa Catarina" (ANUÁRIO CATARINENSE, 1949, p. 79).

${ }^{4}$ Periódico oficial do Inep, a Rbep foi fundada no ano de 1944 e fez circular debates e projetos educacionais, veiculando não apenas informações referentes ao Brasil, mas também artigos e notícias "do estrangeiro".

5 A autora apoia-se em Pierre Bourdieu ao falar sobre "discursos performáticos", e os caracteriza como discursos que pretendem "alterar aquilo que descrevem" (GIL, 2008, p. 49).

${ }^{6}$ Lourenço Filho (1942) está fazendo referência à atuação, em Santa Catarina, do paulista Sebastião de Oliveira Rocha, que, com permanência entre os anos 1938 e 1940, executou uma série de mudanças na legislação e na organização da educação no Estado, com o objetivo de tornar o ensino mais "moderno".

${ }^{7}$ A leitura de Lourenço Filho (1942) quanto ao papel da "quitação escolar" apaga, ou ao menos relega a um segundo plano, o principal motivo pelo qual a medida foi gestada: servir à causa da nacionalização do ensino. Com o acirramento da política de nacionalização em Santa Catarina em meados dos anos 1930, especialmente após o Estado Novo, foi baixada uma série de normatizações. Em livro intitulado Nacionalização do Ensino: aspectos políticos, D’Aquino (1942) cita algumas dessas medidas, como o Decreto-lei n. 88, de 31 de março de 1938 que, pelo princípio da escola unificada e nacional, instituiu exigências que ocasionaram o fechamento de escolas mantidas por imigrantes europeus ou seus descendentes, como as teuto e as ítalo-brasileiras. Afirma que tal medida não resolveu por completo os problemas de nacionalização daquelas comunidades, pela "resistência passiva" que apresentavam. Foi o Decreto-lei n. 301, de 24 de fevereiro de 1939, em sua leitura, que contribuiu para conter a citada resistência, instituindo a quitação escolar.

${ }^{8}$ Trata-se da Lei Orgânica do Ensino Primário (Decreto-lei n. 8.529) e da Lei Orgânica do Ensino Normal (Decreto-lei n. 8.530), ambas de 2 de janeiro de 1946. Essas leis integraram a chamada Reforma Capanema e fizeram parte do movimento nacional de centralização e padronização ocorrido durante o Estado Novo (1937-1945).

${ }^{9}$ A defesa de uma escola pública, gratuita, coeducativa, laica e sob a responsabilidade do Estado foi uma das tônicas do Manifesto dos Pioneiros da Educação Nova, lançado no ano de 1932. O documento uniu um grupo heterogêneo de agentes sociais que ficaram conhecidos como "pioneiros da educação". Em 1959, parte deles lança um segundo manifesto, intitulado Mais uma vez convocados, que reafirma os princípios defendidos em 1932, num contexto de disputas em torno da tramitação da Lei de Diretrizes e Bases da Educação Nacional, que viria a ser promulgada no ano de 1961.

${ }^{10}$ A denominada Reforma Trindade foi implementada em Santa Catarina no ano de 1935 por Luiz Sanches Bezerra da Trindade. Essa reforma transformou as escolas oficiais de formação docente em institutos de educação, equiparou as particulares e organizou o curso normal em: escola normal primária, escola normal secundária e escola normal superior vocacional (DAROS, 2005). 


\section{REFERÊNCIAS}

ANUÁRIO CATARINENSE. Florianópolis: Imprensa Oficial, n. 2, 1949.

BORNHAUSEN, Irineu. Mensagem apresentada à Legislativa do Estado, em 15 de abril de 1955, pelo Governador Irineu Bornhausen. Florianópolis, 1955.

BOURDIEU, Pierre. Algumas propriedades dos campos. In: BOURDIEU, Pierre. Questões de sociologia. Rio de Janeiro: Marco Zero, 1983. p. 89-94.

BOURDIEU, Pierre. O campo intelectual: um mundo à parte. In: BOURDIEU, Pierre. Coisas Ditas. São Paulo: Brasiliense, 1990. p. 169-180.

BOURDIEU, Pierre. O ponto de vista do autor: algumas propriedades gerais dos campos de produção cultural. In: BOURDIEU, Pierre. As regras da arte: gênese e estrutura do campo literário. São Paulo: Companhia das Letras, 1992. p. 243-316.

BOURDIEU, Pierre. Os usos sociais da ciência: por uma sociologia clínica do campo científico. São Paulo: Editora da UNESP, 2004.

BRASIL. Decreto-Lei n. 8.529, de 2 de janeiro de 1946. Lei Orgânica do Ensino Primário. Diário Oficial da União, Rio de Janeiro, DF, 04 jan. 1946.

BRASIL. Decreto-Lei n. 8.530, de 2 de janeiro de 1946. Lei Orgânica do Ensino Normal. Diário Oficial da União, Rio de Janeiro, DF, 04 jan. 1946.

BRASIL. Lei n. 4.024, de 20 de dezembro de 1961. Fixa as Diretrizes e Bases da Educação Nacional. Diário Oficial da União, Brasília, DF, 27 dez. 1961.

CARVALHO, Murilo Braga de. Introdução. In: BRASIL. Ministério da Educação e Saúde. Instituto Nacional de Estudos Pedagógicos. Organização do Ensino Primário e Normal: Estado de Santa Catarina. Rio de Janeiro: Inep, 1950. p. 7-13. (Publicação n. 53).

DANIEL, Leziany Silveira. João Roberto Moreira (1912-1967): itinerários para uma racionalidade ativa. 2009. 224 p. Tese (Doutorado em Educação) - Universidade Federal do Paraná, Curitiba, 2009.

D’ AQUINO, Ivo. Nacionalização do Ensino: aspectos políticos. 2. ed. Florianópolis, SC: Imprensa Oficial do Estado de Santa Catarina, 1942.

DAROS, Maria das Dores. Formação de professores em Santa Catarina: breves considerações sobre sua história. In: DAROS, Maria das Dores; DANIEL, Leziany Silveira; SILVA, Ana Cláudia da (Org.). Fontes históricas: contribuições para o estudo da formação de professores catarinenses (1883-1946). Florianópolis: NUP/CED/UFSC, 2005. p. 11- 22. 
GIL, Natália de Lacerda. Os Boletins do Inep e "a obra de racionalização do aparelhamento escolar" (ou de como hierarquizar os Estados a partir de índices educacionais). In: MORAES, Jair Santana (Org.). O Inep na visão de seus pesquisadores. Brasília, DF: Inep, 2008. p. 43-66.

LOURENÇO FILHO, Manoel Bergström. Introdução. In: BRASIL. Ministério da Educação e Saúde. Instituto Nacional de Estudos Pedagógicos. Organização do Ensino Primário e Normal: XVI - Estado de Santa Catarina. Rio de Janeiro: Inep, 1942. p. 7-13. (Boletim n. 21).

LOURENÇO FILHO, Manoel Bergström. Preparação de pessoal docente para escolas primárias rurais. Revista Brasileira de Estudos Pedagógicos, Rio de Janeiro, v. 20, n. 52, p. 61-104, out./dez. 1953. MANNHEIM, Karl. O homem e a sociedade: estudo sobre a estrutura social moderna. Rio de Janeiro: Zahar, 1962.

MENDONÇA, Ana Waleska P. C.; XAVIER, Libânia Nacif. Uma política nacional de formação de professores. In: CONGRESSO BRASILEIRO DE HISTÓRIA DA EDUCAÇÃO, 4., 2006, Goiânia. Anais... Goiânia: SBHE, nov. 2006.

MICELI, Sérgio. Intelectuais e classe dirigente no Brasil (1920-1945). São Paulo: DIFEL, 1979.

MOREIRA, João Roberto. A educação em Santa Catarina: sinopse apreciativa sobre a administração, as origens e a difusão de um sistema estadual de educação. Brasília, DF: MEC/Inep/Cileme, 1954. (Publicação n. 2).

NUNES, Clarice. Formação docente no Brasil: entre avanços legais e recuos pragmáticos. Teias, Rio de Janeiro, ano 1, n. 1, p. 16-30, jan./jun. 2000.

PÉCAUT, Daniel. Os intelectuais e a política no Brasil: entre o povo e a nação. São Paulo: Ática, 1990.

PEREIRA, Elaine Aparecida Teixeira; DAROS, Maria das Dores. Princípios da Escola Nova na educação catarinense em meados do século XX: olhares de João Roberto Moreira e Orlando Ferreira de Melo. In: COLÓQUIO ENSINO MÉDIO, HISTÓRIA E CIDADANIA, 8., 2013, Florianópolis. Anais... Florianópolis, SC: UDESC, out. 2013.

RBEP. Revista Brasileira de Estudos Pedagógicos, Rio de Janeiro, v. 15, n. 42, abr./jun. 1951.

RBEP. Revista Brasileira de Estudos Pedagógicos, Rio de Janeiro, v. 17, n. 46, abr./jun. 1952.

SANTA CATARINA. Decreto-Lei n. 301, de 24 de fevereiro de 1939. Estabelece normas para a obrigatoriedade do ensino primário, institui a quitação escolar e cria o registro do censo escolar. Coleção de decretos-leis de 1939, Florianópolis, SC, 1939.

SANTA CATARINA. Decreto-Lei n. 257, de 21 de outubro de 1946. Expede a Lei Orgânica do Ensino Normal no Estado de Santa Catarina. Legislação de 1946 - Estado de Santa Catarina. Florianópolis, SC, 1946. p. 100-107. 
SCHNEIDER, Juliete. A democratização do acesso ao ensino secundário pela expansão do ciclo ginasial normal em Santa Catarina (1946-1969). 2008. 130 p. Dissertação (Mestrado em Educação) Universidade Federal de Santa Catarina, Florianópolis, SC, 2008.

SILVA, Ricardo. O Contextualismo Linguístico na História do Pensamento Político: Quentin Skinner e o Debate Metodológico Contemporâneo. DADOS: Revista de Ciências Sociais, Rio de Janeiro, v. 53, n. 2, p. 299-335, 2010.

SKINNER, Quentin. Introdução. In: SKINNER, Quentin. As fundações do pensamento político moderno. São Paulo: Companhia das Letras, 1996.

SKINNER, Quentin. Visões da política: sobre os métodos históricos. Algés, PT: Difel, 2005.

TIBALLI, Elianda Figueiredo Arantes. O fracasso da escola pública no discurso educacional brasileiro: INEP 1944-1964. In: CONGRESSO BRASILEIRO DE HISTÓRIA DA EDUCAÇÃO, 5., 2008, Aracajú. Anais... Aracajú: CBHE, nov. 2008.

VIEIRA, Carlos Eduardo. Intelectuais e o discurso da modernidade na I Conferência Nacional de Educação (Curitiba, 1927). In: BENCOSTA, Marcus Levi (Org.). Culturas escolares, saberes e práticas educativas: itinerários históricos. São Paulo: Cortez, 2007. p. 379-400.

VIEIRA, Carlos Eduardo. Intelligentsia e intelectuais: sentidos, conceitos e possibilidades para a história intelectual. Revista Brasileira de História da Educação, Campinas, SP,v. 1, n. 16, p. 63-85, jan./abr. 2008.

VIEIRA, Carlos Eduardo. Erasmo Pilotto: identidade, engajamento político e crenças dos intelectuais vinculados ao campo educacional no Brasil. In: LEITE, Juçara Luzia; ALVES, Claudia (Org.).

Intelectuais e História da educação no Brasil: poder, cultura e políticas. Vitória, ES: EdUFES, 2011. p. 25-54. 

seus professores (Santa Catarina 1942-1955)

Places, actions and intentions as possibilities of analysis: discourses about rural elementary schools and the education of their teachers (Santa Catarina 1942-1955)
Lugares, acciones e intenciones como posibilidades de análisis: discursos sobre la escuela primaria rural y la formación de sus profesores (Santa Catarina 1942-1955)

\section{Resumen}

El presente texto tiene como foco el análisis de los discursos producidos sobre la escuela primaria rural catarinense y la formación de sus profesores, los cuales ora exaltaban la excelencia de tal escuela y formación, y en otros momentos la calificaban como precarias y deficientes. A partir de fuentes de investigación como libros, publicaciones oficiales, documentos de organismos relacionados a la educación, discursos de los gobernantes, entre otros. El análisis se auxilia en autores como Quentin Skinner (1996; 2005), Pierre Bourdieu (1983; 1990; 1992; 2004), y Carlos Eduardo Vieira (2007; 2008; 2011), que sugieren una atención especial al lugar de donde hablan los agentes sociales, sus intenciones al escribir, así como los embates relacionados a los discursos producidos. Como producto de las formulaciones de los agentes relacionados al campo educacional en situaciones de interlocución y en la actuación pública, los discursos de los intelectuales están relacionados al marco teórico, ideológico y lingüístico disponible en su contexto de producción, a las cuestiones, atravesados por los debates y los embates allí puestos, articulados a proyectos y a programas de acción. Los discursos aquí analizados proponen acciones e intervenciones en el campo educacional, construyendo interpretaciones, prescribiendo y legitimando prácticas. Presentan las contradicciones en las evaluaciones sobre la calidad de la educación catarinense, las cuales dependen de las variables utilizadas para medir "tal" calidad y están relacionadas a las intenciones y a los lugares de donde hablan los autores de los discursos. 
Keywords: Elementary School. Teacher Education. Rural Education.

Elaine Aparecida Teixeira Pereira

E-mail: elaine.tp@gmail.com

Maria das Dores Daros

E-mail: m.daros@ufsc.br
Palabras claves: Escuela primaria. Formación de profesores. Educación rural.

Enviado em: 3/11/2014

Aprovado em: 21/7/2015 